\title{
Detrüsör Așırı Aktivitesi Olan Omurilik Hasarlı Olgularda Sakral Dermatomal Transkutanöz Nörostimülasyon
}

\section{Sacral Dermatomal Transcutaneous Neurostimulation in Patients with Spinal Cord Injury and Overactive Detrusors}

\author{
Engin KOYUNCU, Murat ERSÖZ, Asuman DOĞAN, Neşe ÖZGIRGIN \\ Sağılk Bakanlığı Ankara Fizik Tedavi ve Rehabilitasyon Eğitim ve Araştırma Hastanesi, Ankara, Türkiye
}

\section{Özet}

Amaç: Çalışmamızda sakral dermatomal transkutanöz elektriksel nörostimülasyon (SDTENS) metodunun omurilik hasarına bağlı detrüsör aşırı aktivitesinde etkinliğini değerlendirdik.

Gereç ve Yöntem: Aşırı aktif detrüsörü olan 18 omurilik hasarlı hasta (15 erkek, 3 kadın) çalışmaya dahil edildi ve randomize olarak stimülasyon ve kontrol gruplarına ayrıldı. Tüm hastalara oral antikolinerjik ilaç (Oksibutinin $\mathrm{HCl}$ ) tedavisi verildi. Stimülasyon grubundaki hastaların tedavisine üç haftalık transkutanöz elektriksel stimülasyon eklendi.

Bulgular: Stimülasyon ve kontrol gruplarında tedavi öncesi ve sonrası ortalama maksimum sistometrik kapasiteler sırasıyla $92,1 \pm 43,6 \mathrm{ml}$, $226,6 \pm 133,1 \mathrm{ml}(p=0,008)$ ve $92,3 \pm 47,0 \mathrm{ml}, 222,1 \pm 178,2 \mathrm{ml}(p=0,066)$ olarak saptandı. Stimülasyon ve kontrol gruplarında ortalama artışlar sırasıyla \%189 ve \%170 olarak saptandı $(p>0,05)$.

Sonuç: Aşırı aktif detrüsörlü omurilik hasarlı hastalarda oral antikolinerjik tedaviye ek olarak uygulanan SDTENS tedavisi ile mesane kapasitesinde istatistiksel olarak anlamlı artış sağlanırken, aynı süreyle sadece antikolinerjik tedavi alan hastalarda kapasitedeki artış anlamlılık sınırına ulaşmamıştır. SDTENS, bu hasta grubunda olası bir adjuvan tedavi seçeneği olarak ortaya çıksa da, bu yöntemin etkinliğini göstermek için daha büyük hasta gruplarında yapılacak çalışmalara gereksinim vardır. Türk Fiz Tip Rehab Derg 2011;57:212-5.

Anahtar Kelimeler: Transkutanöz elektriksel stimülasyon, aşırı aktif detrüsör, omurilik hasarı

\section{Summary}

Objective: In our study, we evaluated the efficacy of sacral dermatomal transcutaneous electrical neurostimulation (SDTENS) in patients with spinal cord injury $(\mathrm{SCl})$ who had overactive detrusors.

Materials and Method: Eighteen patients ( 15 males, 3 females) with $\mathrm{SCl}$ who had overactive detrusors were included in the study and were assigned to stimulation and control groups randomly. All patients were given anticholinergic agent (Oxybutinin $\mathrm{HCl}$ ). In the stimulation group, transcutaneous electrical stimulation was added to the treatment for three weeks.

Results: The mean pre- and post-treatment maximum cystometric capacities in the stimulation and control groups were $92.1 \pm 43.6 \mathrm{ml}$, $226.6 \pm 133.1 \mathrm{ml}(p=0.008)$ and $92.3 \pm 47.0 \mathrm{ml}, 222.1 \pm 178.2 \mathrm{ml}$, respectively $(p=0.066)$ and the mean increases were $189 \%$ and $170 \%$ ( $p>0.05)$.

Conclusion: Statistically significant increase was achieved in bladder capacity by SDTENS+oral anticholinergic therapy in patients with $\mathrm{SCI}$ who had overactive detrusors, while increase in bladder capacity did not reach level of statistical significance in patients who were treated with oral anticholinergic medication alone in the same treatment duration. Although SDTENS appears to be a possible adjuvant treatment option in this patient group, new studies with larger sample sizes are needed to demonstrate the efficacy of this method. Turk J Phys Med Rehab 2011;57:212-5.

Key Words: Transcutaneous electrical stimulation, overactive detrusor, spinal cord injury 


\section{Giriş}

Omurilik hasarına bağlı nörojenik mesane disfonksiyonu gelişen hastalarda detrüsör aşırı aktivitesi, vezikoüreteral reflü, hidronefroz, piyelonefrit, böbrek yetmezliği, kronik üriner sistem enfeksiyonu, mesane taşı, mesane divertikülü, mesane kanseri gibi komplikasyonlar ortaya çıkabilir. Omurilik hasarlı hastalarda nörojenik mesane tedavisinin amaçları düşük basınçta idrar depolama ve düşük detrüsör basınçları ile etkili mesane boşalması sağlanarak, yüksek mesane içi basınca bağlı gelişebilecek alt ve üst üriner sistem komplikasyonlarından korumak ve istemsiz idrar kaçaklarını önleyerek toplumsal entegrasyonun kolaylaştırılmasıdır (1).

Nörojenik detrüsör aşırı aktivitesi sıklıkla sakral refleks arkın korunduğu suprasakral omurilik yaralanmalı hastalarda, ürodinamik çalışmanın dolum fazında, spontan veya uyarılış, istemsiz detrüsör kontraksiyonu olarak tanımlanır (2).

Mesane içi basıncı azaltmak ve mesane kapasitesini artırmak için nörojenik detrüsör aşırı aktivitesinin birinci basamak tedavisinde oral antikolinerjik ilaçlarla birlikte mesaneyi boşaltmak ve rezidüel idrar miktarını azaltmak için temiz aralıklı kateterizasyon kullanılır (3).

S3 segmental sinir köklerinin, cerrahi yöntemlerle implante edilen elektrotlarla direk elektriksel stimülasyonunun nörojenik detrüsör aşırı aktivitesinde başarılı sonuçlar ortaya çıkarması S3 dermatomuna yüzeyel elektrotlar ile transkutanöz elektriksel nörostimülasyon (TENS) uygulamasını gündeme getirmiştir (4-7).

Çalışmamızda hasta tarafından kolay uygulanabilen, belirgin yan etkisi olmayan, tedavi maliyeti nispeten düşük, invaziv olmayan ve pratik bir yöntem olduğu düşünülen sakral dermatomal transkutanöz elektriksel nörostimülasyonun (SDTENS) omurilik hasarlı olgularda görülen detrüsör aşırı aktivitesine etkinliğini test etmek amaçlandı.

\section{Gereç ve Yöntem}

Çalışmaya hastanemizde 2007-2008 tarihlerinde yatarak rehabilitasyon programına alınan, omurilik hasarına bağlı alt üriner sistem disfonksiyonu nedeniyle ürodinami laboratuvarına gönderilen, aşırı aktif detrüsör nedeniyle oral antikolinerjik tedavi (Oksibutinin $\mathrm{HCl} 5$ mg tb 3x1 aç karnına) başlanan 18 hasta dahil edildi. Hastalar randomize olarak (omurilik hasarına bağlı alt üriner sistem disfonksiyonu nedeniyle ürodinami laboratuvarına gönderilen hastalardan ürodinami laboratuvarına geliş sırası tek sayı olanlar çalışma grubuna, çift sayı olanlar kontrol grubuna alındı) çalışma ve kontrol gruplarına ayrıldı. Çalışma hastanemizin Eğitim Planlama Komisyonu tarafından onaylandı ve tüm hastalara çalışma hakkında bilgi verilerek yazılı bilgilendirilmiş onamları alındı.

Ürodinamik çalışma öncesi tüm hastaların nörolojik ve sistemik muayeneleri yapıldı, alt ve üst üriner sisteme yönelik intravenöz piyelografi, üriner sistem ultrasonografisi, böbrek fonksiyon testleri (kanda üre ve kreatinin), tam idrar tetkiki ve idrar kültürü değerlendirmeleri yapıldı. Tüm hastalarda yaş, cinsiyet, hastalık süresi, etiyoloji, nörolojik seviye, mesane boşaltma yöntemi ve kullanılan ilaçlar kaydedildi.

Çalışma grubundaki hastalara oksibutinin tedavisine ek olarak bilateral S3 dermatomlarına (Resim 1) haftada beş gün, günde bir saat toplam 15 seans transkutanöz stimülasyon uygulandı. Uygulama silikon yüzeyel elektrotlar ile yapıldı. Akım şiddeti hastayı rahatsız etmeyecek en yüksek şiddette ayarlandı, S3 dermatomunda anestezi olan hastalarda akım şiddeti hastanın duyusunun korunmuş olduğu bir bölgede transkutanöz stimülasyon denenerek hastayı rahatsız etmeyecek en yüksek akım şiddeti bulunarak ayarlandı. Akım frekansı $20 \mathrm{~Hz}$, impuls süresi 200 mikrosaniye olarak uygulandı. Stimulus süresi olarak 200 mikrosaniye seçilmesinde 300 mikrosaniye altındaki stimulus sürelerinde stimülasyona bağlı ağrının az oluşu, toleransın iyi oluşu, frekans olarak $20 \mathrm{~Hz}$ seçilmesinde tetanizan frekans olan 30-35 Hz'in altında kalınmasının tercih edilmesi belirleyici oldu.

Ürodinamik incelemeler Libra+ (MMS, Enschede, The Netherlands) ürodinamik ölçüm sistemiyle, çift lümenli $8 \mathrm{~F}$ steril üretral kateterler ve oda sıcaklığındaki steril serum fizyolojik kullanılarak $50 \mathrm{ml} /$ dakika sabit dolum hızıyla yapıldı. Kontrol ürodinamik incelemeler tedavinin bitiminden sonraki gün yapıldı. Hastaların işemeyi daha fazla geciktiremiyeceğini bildirdiği, duyusu olmayan hastalarda ise belirgin idrar kaçağı ya da işemenin olduğu ya da intravezikal basıncın $40 \mathrm{cmH}_{2} \mathrm{O}^{\prime} \mathrm{yu}$ aştığı andaki hacim maksimum sistometrik kapasite olarak kabul edildi. İşeme fazından sonra rezidü idrar kalıp kalmadığı ve miktarı kateter yardımıyla tespit edildi. Çalışma ve kontrol grubundaki hastaların tedavi öncesi ve sonrası maksimum sistometrik kapasiteleri belirlendi.

İstatistiksel analizler SPSS Windows 10.00 paket programı kullanılarak yapıldı. Çalışma ve kontrol grupları yaş, hastalık süresi ve tedavi öncesi maksimum sistometrik kapasite açısından MannWhitney $U$ testi, cinsiyet ve nörolojik seviye dağılımı açısından Kikare testi kullanılarak karşılaştıııldı. Çalışma ve kontrol gruplarında tedavi öncesi ve sonrası ortalama sistometrik kapasiteler Wilcoxon Signed Rank testi, çalışma ve kontrol gruplarında tedavi sonrası elde edilen artışlar Mann-Whitney U testi kullanılarak karşılaştırıldı, $\mathrm{p}<0,05$ değeri anlamlı kabul edildi.

\section{Bulgular}

Beş hastada $(\% 27,8)$ servikal, 13 hastada $(\% 72,2)$ torakal lezyon vardı. ASIA sınıflamasına göre hastaların $11^{\prime} \mathrm{i}(\% 61,1)$ A, 4'ü $(\% 22,2)$ B, 2'si $(\% 11,1)$ C ve 1'i $(\% 5,6)$ ASIA D idi. Çalışma ve kontrol grubuna alınan hastaların demografik ve klinik özellikleri Tablo 1'de sunulmuştur. Çalışma ve kontrol grupları arasında yaş, hastalık süresi, cinsiyet ve nörolojik seviyeler açısından istatistiksel olarak anlamlı fark yoktu (Tablo 1). ASIA sınıfı ve etiyoloji değerlendirmelerinde 4'er alt grup oluşması ve her gruptaki hasta sayılarının çok düşük olması nedeniyle istatistiksel karşılaştırma yapılamadı.

Çalışma ve kontrol gruplarının tedavi öncesi ortalama maksimum sistometrik kapasiteleri istatistiksel olarak farksızdı (Tablo 2). Çalışma grubunda tedavi öncesi ve sonrası ortalama maksimum sistometrik kapasiteler sırasıly $92,1 \pm 43,6 \mathrm{ml}$, $226,6 \pm 133,1 \mathrm{ml}(\mathrm{p}=0,008)$ iken, kontrol grubunda $92,3 \pm 47,0 \mathrm{ml}$, $222,1 \pm 178,2 \mathrm{ml}(p=0,066)$ olarak saptandı. Çalışma grubunda tedavi öncesine göre tedavi sonrası ortalama maksimum sistometrik kapasitede istatistiksel olarak anlamlı artış saptandı $(p=0,008)$. Kontrol grubunda tedaviyle maksimum sistometrik kapasitede belirgin artış gözlendi ancak bu artış istatistiksel anlamlılık düzeyine ulaşmadı $(p=0,066)$. Çalışma grubunda

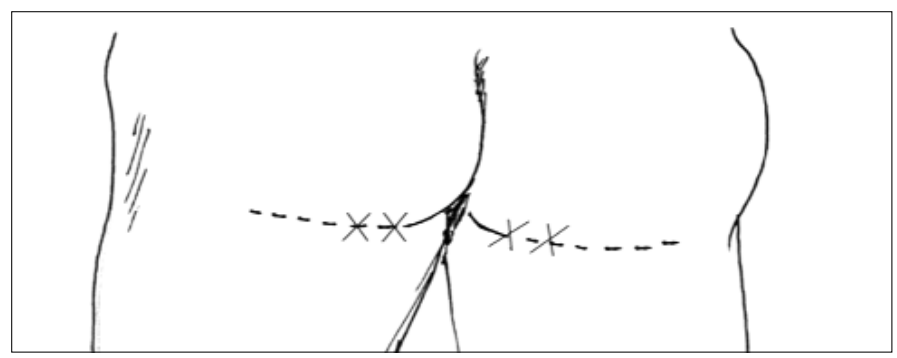

Resim 1. Transkutanöz stimülasyon uygulama alanı. 
ortalama artış yüzdesi $188,7 \pm 60,4$ iken, kontrol grubunda $170,1 \pm 77,9$ olarak belirlendi ( $p>0,05)$. Tedavi öncesine göre tedavi sonrası ortalama maksimum sistometrik kapasitelerde meydana gelen değişim miktarları karşılaştıııldığında, gruplar arasında istatistiksel olarak anlamlı fark saptanmadı $(p>0,05)$ (Tablo 2). Çalışma süresince belirgin bir yan etki gözlenmedi.

\section{Tartışma}

Oral antikolinerjik ilaçların ağız kuruluğu, konstipasyon, dispepsi, görsel akomodasyon değişiklikleri, baş dönmesi ve somnolans gibi yan etkileri hastaların tedaviye uyumlarını azaltabilmektedir (8). Oral antikolinerjik ilaçlara dirençli veya yan etki nedeniyle oral antikolinerjik ilaç kullanamayan hastaların tedavisinde intravezikal oksibutinin, kapsaisin veya resiniferatoksin, detrüsör kasına botulinum toksin enjeksiyonu, elektrik stimülasyonu ve posterior sakral kök rizotomi (1,9-11,13-16), mesane augmentasyon sistoplastisi yöntemleri kullanılabilir. Çalışmamızda aşırı aktif detrüsörlü omurilik hasarlı hastalarda oral antikolinerjik tedavi olarak

Tablo 1. Çalışma ve kontrol gruplarının genel özellikleri.

\begin{tabular}{|c|c|c|c|}
\hline & $\begin{array}{c}\text { Oral antikolinerjik } \\
\text { ilaç+SDTENS (n=9) }\end{array}$ & $\begin{array}{c}\text { Oral antikolinerijk } \\
\text { ilaç }(\mathbf{n = 9})\end{array}$ & $\mathbf{p}$ \\
\hline Yaş (yıl) & $32,6 \pm 5,3$ & $30,1 \pm 4,2$ & $>0,05$ \\
\hline Hastalık süresi (ay) & $27(4-120)$ & $27,5(4-144)$ & $>0,05$ \\
\hline Cinsiyet & & & \\
\hline Kadın & $3(\% 33,3)$ & $0(\% 0)$ & $>0,05$ \\
\hline Erkek & $6(\% 66,7)$ & $9(\% 100)$ & \\
\hline Lezyon seviyesi & & & \\
\hline Servikal & $3(\% 33,3)$ & $2(\% 22,2)$ & $>0,05$ \\
\hline Torakal & $6(\% 66,7)$ & $7(\% 77,8)$ & \\
\hline ASIA sınıfı & & & \\
\hline A/B/C/D & $6 / 1 / 1 / 1$ & $5 / 3 / 1 / 0$ & \\
\hline Etiyoloji & & & \\
\hline Trafik Kazası & 2 & 2 & \\
\hline Yüksekten düşme & 5 & 4 & \\
\hline Ateşli silahla yaralanma & 1 & 3 & \\
\hline Tümör & 1 & 0 & \\
\hline
\end{tabular}

SDTENS: Sakral Dermatomal Transkutanöz Elektriksel Nörostimülasyon

ASIA: American Spinal Injury Association oksibutinin seçilmesinde omurilik hasarlı olgularda bu ajanla olan yoğun ve olumlu deneyimler ve bu ürünün ucuz ve kolay bulunur olması belirleyici oldu.

Nöromodülasyon nörojenik ve nörojenik olmayan alt üriner sistem disfonksiyonu tedavisinde intravezikal elektriksel stimülasyon, direk mesane stimülasyonu, pelvik sinir stimülasyonu, pudendal sinir stimülasyonu, sakral spinal stimülasyon, dorsal rizotomi ile birlikte sakral anterior kök stimülasyonu, uyluk kaslarının elektriksel stimülasyonu, posterior tibial sinir stimülasyonu ve TENS (suprapubik veya S2-S3 dermatomlarına) gibi birçok değişik teknik ve cihazlarla uygulanmaktadır $(4,14,17-22)$. S3 segmental sinir köklerinin cerrahi yöntemlerle implante edilen elektrotlarla direkt elektriksel stimülasyonu sonucu nörojenik detrüsör aşırı aktivitesinde başarıı sonuçlar alınması, daha kolay uygulanabilen, invaziv olmayan, belirgin yan etkisi bulunmayan, tedavi maliyeti daha düşük bir yöntem olan S3 dermatomuna yüzeyel elektrotlar ile TENS uygulamasını gündeme getirmiştir (4-7). Detrüsör ve levatör kasları temel olarak 3. sakral sinirden innerve olurlar ve S3 aktivitesinin modülasyonunun, detrüsör aşırı aktivitesi tedavisinde etkili olduğu gösterilmiştir $(23,24)$. TENS'in detrüsör aşırı aktivitesine etki mekanizması net olmamakla birlikte, santral olarak serebrospinal endorfin düzeyinin artması yoluyla detrüsör aktivitesini azalttığı, ayrıca periferik etki ile sakral kök stimülasyonu sonucu eksternal üretral sfinkter aktivasyonuna yol açarak detrüsör aktivitesini azalttığı ileri sürülmektedir $(25,26)$. Diğer olası mekanizmalar tekrarlayan duyusal stimülasyonun ardından spinal düzeydeki desensitizasyona bağlı ortaya çıkan duyusal habitüasyon ve aynı kökten inerve kaslarda oluşan kontraksiyonlara bağlı Renshaw hücreleri aracılığıyla gelişen rekürren inhibisyondur.

Nörojenik ve nörojenik olmayan mesane sorunlarının tedavisinde kullanılan TENS stimülasyon parametrelerinin seçiminde fikir birliği yoktur. Değişik hasta gruplarında değişik yöntem ve parametrelerle uygulanan çalışmalar mevcuttur $(3,6,7,22,23,27-31)$. Omurilik hasarlı 22 hastada yapılan bir çalışmada, akım frekansı $50 \mathrm{~Hz}$, impuls süresi 200 mikrosaniye, akım şiddeti 15-20 mA, stimülasyon süresi 15 dakika olarak ayarlanmış, 30 seans tedavi uygulanmış ve mesane fonksiyonlarında (maksimum sistometrik kapasitede artış, rezidüel idrar miktarında azalma) belirgin iyileşme bildirilmiştir (30). Skeil ve ark.(32)' nın nörolojik hastalıklara bağlı üriner sorunları olan 44 hastada yaptıkları çalıșmada, akım frekansı $20 \mathrm{~Hz}$, impuls süresi 200 mikrosaniye olarak seçilmiş, günde iki kez, stimülasyon süresi 90 dakika, altı hafta boyunca uygulanan tedavi sonucunda maksimum sistometrik kapasitede istatistiksel olarak anlamlı artış saptanmamıştır. Çalışmalardan elde edilen farklı sonuçlar, uygulanan tedavi yöntemlerindeki akım frekanslarının, akım şiddetlerinin ve stimülasyon sürelerinin farklı olmasından kaynaklanıyor olabilir.

Çalışmamızda, aşırı aktif detrüsörlü omurilik hasarlı hastalarda oral antikolinerjik tedaviye ek olarak bilateral S3 dermatomlarına, akım frekansı $20 \mathrm{~Hz}$, impuls süresi 200 mikrosaniye olacak şekilde ve günde bir saat olmak üzere, 15 seans transkutanöz stimülasyon

Tablo 2. Çalışma ve kontrol gruplarının tedavi öncesi ve tedavi sonrası maksimum sistometrik kapasite değerlerinin grup içinde ve gruplar arasında karşılaştırıması.

\begin{tabular}{|l|c|c|c|c|c|}
\hline & V1 $(\mathrm{ml})$ & V2 (ml) & p & Artış (ml) & Artış (\%) \\
\hline Oral antikolinerjik ilaç + SDTENS & $92,1 \pm 43,6$ & $226,6 \pm 133,1$ & 0,008 & $134,4 \pm 40,5$ & $188,7 \pm 60,4$ \\
\hline Oral antikolinerjik ilaç & $92,3 \pm 47,0$ & $222,1 \pm 178,2$ & 0,066 & $129,7 \pm 54,7$ & $170,1 \pm 77,9$ \\
\cline { 2 - 6 } & $p>0,05$ & $p>0,05$ & & $p>0,05$ \\
\hline
\end{tabular}

V1: Tedavi öncesi maksimum sistometrik kapasite $(\mathrm{ml})$

V2: Tedavi sonrası maksimum sistometrik kapasite $(\mathrm{ml})$ 
uygulanan SDTENS tedavisi ile mesane kapasitesinde istatistiksel olarak anlamlı artış sağlanırken, aynı süreyle sadece antikolinerjik tedavi alan hastalarda, kapasitedeki artış anlamlılık sınırına ulaşmamıştır, buna karşılık meydana gelen değişim miktarları karşılaştırıldığında, gruplar arasında istatistiksel olarak anlamlı fark olmadığı gözlenmiştir. SDTENS, bu hasta grubunda olası bir adjuvan tedavi seçeneği olarak ortaya çıksa da, bu yöntemin etkinliğini göstermek için daha büyük hasta gruplarında yapılacak çalışmalara gereksinim olduğunu düşünmekteyiz.

Çalışmamızda, oral antikolinerjik ilaç+SDTENS ve sadece oral antikolinerjik ilaç grupları karşılaştırıldığında, daha önce yapılmış bazı çalışmalardan farklı olarak mesane kapasitesindeki artışlarda gruplar arasında istatistiksel olarak anlamlı fark saptanmamasında, çalışma ve kontrol gruplarının az sayıda hasta içeriyor olması, uygulama yeri, süresi, yöntemi ve seçilen tedavi parametrelerinin farklı olmasının rolü olabilir. Bunun yanında üç kadın hastanın SDTENS grubunda bulunması ve kadın hasta sayısının nispeten az olması çalışmamızın bir kısıtlılığı olarak görünmektedir.

Birçok çalışmacı, nörojenik mesane tedavisinde elektriksel stimülasyonun etkin ve güvenilir bir tedavi seçeneği olduğunu vurgulamaktadır, ancak hasta gruplarında ve seçilen tedavi parametrelerinde standardizasyon olmadığından, farklı çalışmaların sonuçlarının karşılaştıııması güçleşmektedir. Ayrıca omurilik hasarlı hastalarda yüzeyel elektrotlarla yapılmış çalışma sayısı nispeten azdır, yapılmış çalışmaların büyük bir kısmı nörojenik olmayan detrüsör instabiliteli hasta grupları ile ilgilidir. Bu nedenle bu tedavi yönteminin omurilik hasarlı hastalarda etkinliğini göstermek için benzer ve daha büyük hasta gruplarında, benzer ve farklı parametrelerle, tedavinin uzun dönem etkinliğini de test eden yeni çalışmalara ihtiyaç vardır. Yapılacak yeni çalışmalarda elde edilecek pozitif sonuçlar iğne elektroda gerek duyulmadan birçok hastanın kendi başına ev koşullarında uygulayabileceği, istenmeyen etkisi az, pratik ve nispeten ekonomik bir yöntem olan SDTENS'in detrüsör aşırı aktivitesi olan omurilik hasarlı olgularda tek başına ya da antikolinerjik tedaviye ek iyi bir tedavi seçeneği olarak geliştirilmesine katkı sağlayacaktır.

\section{Çıkar Çatışması:}

Yazarlar herhangi bir çıkar çatışması bildirmemişlerdir.

\section{Kaynaklar}

1. Samson G, Cardenas DD. Neurogenic bladder in spinal cord injury. Phys Med Rehabil Clin N Am 2007;18:255-74.

2. Abrams P, Cardozo L, Fall M, Griffiths D, Rosier P, Ulmsten U, et al. The standardisation of terminology in lower urinary tract function: Report from the standardisation sub-committee of the International Continence Society. Urology 2003;61:37-49.

3. Hansen J, Media S, Nøhr M, Biering-Sørensen F, Sinkjaer T, Rijkhoff NJ. Treatment of neurogenic detrusor overactivity in spinal cord injured patients by conditional electrical stimulation. J Urol 2005;173:2035-9.

4. Van Rey FS, Heesakkers JP. Applications of neurostimulation for urinary storage and voiding dysfunction in neurological patients. Urol Int 2008;81:373-8.

5. Wallace PA, Lane FL, Noblett KL. Sacral nerve neuromodulation in patients with underlying neurologic disease. Am J Obstet Gynecol 2007; 197:96.e1-5.

6. Walsh IK, Johnston RS, Keane PF. Transcutaneous sacral neurostimulation for irritative voiding dysfunction. Eur Urol 1999;35:192-6.

7. Hoebeke P, Van Laecke E, Everaert K, Renson C, DE Paepe H, Raes A, et al. Transcutaneous neuromodulation for the urge syndrome in children: a pilot study. J Urol 2001;166:2416-9.

8. Arisco AM, Brantly EK, Kraus SR. Oxybutynin extended release for the management of overactive bladder: a clinical review. Drug Des Devel Ther 2009;3:151-61.
9. Reitz A, Schurch B. Intravesical Therapy options for neurogenic detrusor overactivity. Spinal Cord 2004;42:267-72.

10. Chancellor MB, de Groat WC. Intravesical capsaicin and resiniferatoxin therapy: spicing up the ways to treat the overactive bladde. J Urol 1999;162:3-11.

11. Patki PS, Hamid R, Arumugam K, Shah PJ, Craggs M. Botulinum toxintype $A$ in the treatment of drug-resistant neurogenic detrusor overactivity secondary to traumatic spinal cord injury. BJU Int 2006;98:77-82.

12. Reitz A, Stöhrer M, Kramer G, Del Popolo G, Chartier-Kastler E, Pannek J, et al. European experience of 200 cases treated with botulinum-A toxin injections into the detrusor muscle for urinary incontinence due to neurogenic detrusor overactivity. Eur Urol 2004;45:510-5.

13. Schurch B, Stöhrer M, Kramer G, Schmid DM, Gaul G, Hauri D. Botulinum-A toxin for treating detrusor hyperreflexia in spinal cord injured patient: a new alternative to anticholinergic drugs? J Urol 2000;164:692-7.

14. Vignes JR, Bauchet L, Ohanna F. Dorsal rhizotomy combined with anterior sacral root stimulation for neurogenic bladder. Acta Nurochir Suppl 2007;97:323-31.

15. Chen JL, Kuo HC. Long-term outcomes of augmentation enterocystoplasty with an ileal segment in patients with spinal cord injury. J Formos Med Assoc 2009;108:475-80.

16. Queek ML, Ginsberg DA. Long-term urodynamics follow up bladder augmentation for neurogenic bladder. J Urol 2003;169:195-8.

17. Van Balken MR, Vergunst $H$, Bemelmans BL. The use of electrical devices for the treatment of bladder dysfunction: A review of methods. J Urol 2004;172:846-51.

18. Wyndaele JJ. Clinical outcome of sacral neuromodulation in incomplete spinal cord injured patients suffering from neurogenic lower urinary tract symptoms. Spinal Cord 2009;47:427.

19. Van Kerrebroeck EV, Van der Aa HE, Bosch JL, Koldewijn EL, Vorsteveld JH, Debruyne FM. Sacral rhizotomies and electrical bladder stimulation in spinal cord injury. Part I: Clinical and urodynamic analysis. Dutch study group on sacral anterior root stimulation. Eur Urol 1997;31:263-71.

20. Amarenco G, Ismael SS, Even-Schneider A, Raibaut P, Demaille-Wlodyka $S$, Parratte $B$, et al. Urodynamic effect of acute transcutaneous posterior tibial nerve stimulation in overactive bladder. J Urol 2003;169:2210-5.

21. Spinelli M, Malaguti S, Giardiello G, Lazzeri M, Tarantola J, Van Den Hombergh U. A new minimally invasive procedure for pudendal nerve stimulation to treat neurogenic bladder: Description of the method and preliminary data. Neurourol Urodyn 2005;24:305-9.

22. Horvath EE, Yoo PB, Amundsen CL, Webster GD, Grill WM. Conditional and continuous electrical stimulation increase cystometric capacity in person with spinal cord injury. Neurourol Urodyn 2010;29:401-7.

23. Soomro NA, Khadra MH, Robson W, Neal DE. A crossover randomized trial of transcutaneous electrical nerve stimulation and oxybutynin in patients with detrusor instability. J Urol 2001;166:146-9.

24. Tanagho EA, Schmidt RA. Electrical stimulation in the clinical management of the neurogenic bladder. J Urol 1988;140:1331-9.

25. Murray KH. Re: Treatment of motor and sensory detrusor instability by electrical stimulation; and Re: The neurophysiological basis of bladder inhibition in response to intravaginal electrical stimulation. J Urol 1984;131:356.

26. Tanagho EA. Concept of neuromodulation. Neurourol Urodyn 1993;12:487-8.

27. Malm-Buatsi E, Nepple KG, Boyt MA, Austin JC, Cooper CS. Efficacy of transcutaneous electrical nerve stimulation in children with overactive bladder refractory to pharmacotherapy. Urology 2007;70:980-3.

28. Hasan ST, Robson WA, Pridie AK, Neal DE. Transcutaneous electrical nerve stimulation and temporary S3 neuromodulation in detrusor instability. J Urol 1996;155:2005-11.

29. Bower WF, Moore KH, Adams RD. A pilot study of the home application of transcutaneous neuromodulation in children with urgency or urge incontinence. J Urol 2001;166:2420-2.

30. Radziszewski K, Zielinski H, Radziszewski P, Swiecicki R. Transcutaneous electrical stimulation of urinary bladder in patients with spinal cord injuries. Int Urol Nephrol 2009;41:497-503.

31. Hagstroem S, Mahler B, Madsen B, Djurhuus JC, Rittig S. Transcutaneous electrical nerve stimulation for refractory daytime urinary urge incontinence. J Urol 2009;182:2072-8.

32. Skeil D, Thorpe AC. Transcutaneous electrical nerve stimulation in the treatment of neurological patients with urinary symptoms. BJU Int 2001;88:899-908. 